\title{
BMJ Open Implementing guidelines to routinely prevent chronic vascular disease in primary care: the Preventive Evidence into Practice cluster randomised controlled trial
}

Mark Fort Harris, ${ }^{1}$ Sharon M Parker, ${ }^{1}$ John Litt, ${ }^{2}$ Mieke van Driel, ${ }^{3}$ Grant Russell, ${ }^{4}$ Danielle Mazza, ${ }^{5}$ Upali W Jayasinghe, ${ }^{1}$ Chris Del Mar, ${ }^{6}$ Jane Lloyd, ${ }^{1}$ Jane Smith, ${ }^{6}$ Nicholas Zwar, ${ }^{7}$ Richard Taylor, ${ }^{7}$ Gawaine Powell Davies, ${ }^{1}$ On behalf of the Preventive Evidence into Practice (PEP) Partnership Group

To cite: Harris MF, Parker SM, Litt J, et al. Implementing guidelines to routinely prevent chronic vascular disease in primary care: the Preventive Evidence into Practice cluster randomised controlled trial. BMJ Open 2015;5:e009397. doi:10.1136/bmjopen-2015009397

- Prepublication history for this paper is available online. To view these files please visit the journal online (http://dx.doi.org/10.1136/ bmjopen-2015-009397).

Received 17 July 2015 Revised 2 October 2015 Accepted 13 November 2015

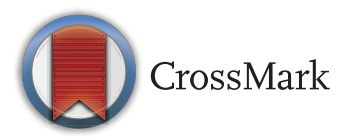

For numbered affiliations see end of article.

Correspondence to Professor Mark Fort Harris; m.f.harris@unsw.edu.au

\section{ABSTRACT}

Objective: To evaluate an intervention to improve implementation of guidelines for the prevention of chronic vascular disease.

Setting: 32 urban general practices in 4 Australian states.

Randomisation: Stratified randomisation of practices.

Participants: 122 general practitioners (GPs) and practice nurses (PNs) were recruited at baseline and 97 continued to 12 months. 21848 patient records were audited for those aged 40-69 years who attended the practice in the previous 12 months without heart disease, stroke, diabetes, chronic renal disease, cognitive impairment or severe mental illness.

Intervention: The practice level intervention over 6 months included small group training of practice staff, feedback on audited performance, practice facilitation visits and provision of patient education and referral information.

Outcome measures: Primary: 1. Change in proportion of patients aged 40-69 years with smoking status, alcohol intake, body mass index (BMI), waist circumference (WC), blood pressure (BP) recorded and for those aged 45-69 years with lipids, fasting blood glucose and cardiovascular risk in the medical record. 2. Change in the level of risk for each factor. Secondary: change in self-reported frequency and confidence of GPs and PNs in assessment.

Results: Risk recording improved in the intervention but not the control group for WC (OR $2.52(95 \% \mathrm{Cl}$ 1.30 to 4.91$)$ ), alcohol consumption (OR $2.19(\mathrm{Cl}$ 1.04 to 4.64$)$ ), smoking status (OR 2.24 (1.17 to 4.29)) and cardiovascular risk (OR 1.50 (1.04 to 2.18)). There was no change in recording of $B P$, lipids, glucose or BMI and no significant change in the level of risk factors based on audit data. The confidence but not reported practices of GPs and PNs in the intervention group improved in the assessment of some risk factors.

\section{Strengths and limitations of this study}

This is a moderately large cluster randomised controlled trial in general practices in four Australian states.

- The intervention was developed in partnership with organisations involved in developing and implementing guidelines for the prevention of chronic vascular conditions in Australian general practice.

- The trial design involved blind random allocation but practitioners were not blinded to their allocation.

- Although provider questionnaires relied on selfreport, medical records were electronically audited and not subject to selection bias.

Conclusions: This intervention was associated with improved recording of some risk factors but no change in the level of risk at the follow-up audit.

Trial registration number: Australian and New Zealand Clinical Trials Register (ANZCTR): ACTRN12612000578808, results.

\section{INTRODUCTION}

Chronic diseases and their risk factors account for most of the global burden of disease. ${ }^{1}$ Nine in 10 adult Australians have at least one of the behavioural or physiological risk factors for chronic disease including smoking, poor nutrition, excessive alcohol consumption, physical inactivity, overweight or obesity, hypertension or dyslipidemia. ${ }^{2}$ General practitioners (GPs) are well placed to work with patients to manage these risk factors because of their high population 
coverage (over $80 \%$ of the population present in primary care at least once a year), and patient acceptance of their role in preventive care. ${ }^{34}$ They are thus in an ideal position to assess and provide advice about lifestyle-related behavioural risk factors. ${ }^{5}$

The roles of GPs in preventive care are reinforced in clinical guideline recommendations from a range of government and non-government organisations. ${ }^{6}{ }^{7}$ A number of these recommendations are based on the '5As' (Ask, Assess, Advise/Agree, Assist and Arrange) framework for a multidisciplinary preventive care..$^{8-10}$ There is evidence that this approach enhances patient motivation and behaviour change. ${ }^{11}$ Despite wide dissemination of preventive guidelines, implementation barriers exist at various patient (eg, motivation and health literacy), practitioner (eg, beliefs about effectiveness), practice (eg, time and organisational capacity) and system (eg, funding and workforce) levels. ${ }^{12-14}$ These barriers contribute to low rates of clinical assessment of risk, lifestyle advice and referral. ${ }^{15-17}$

The Preventive Evidence into Practice (PEP) partnership group developed and conducted a multicenter cluster randomised controlled trial of a practice facilitation and quality improvement intervention designed to support general practices to implement the recommendations of evidence-based clinical management guidelines for the prevention of cardiovascular disease (CVD) and type 2 diabetes. This paper reports on the primary outcome of the trial: the clinical assessment and recording of patient risk factors from audited records. We hypothesised that, for patients aged 40-69 years, the PEP intervention would improve the recording of patient risk factors by $20 \%$, over 12 months.

\section{MATERIALS AND METHODS Design}

We conducted a cluster randomised controlled trial in urban general practices in four Australian states (New South Wales, Victoria, South Australia and Queensland) over 12 months (2012-2013). The methods for the PEP trial were designed a priori, and have been described elsewhere. $^{15}$

\section{Randomisation}

Blinded practice allocation was conducted (by UJ) independent of recruitment or data collection. Practices were randomly assigned to intervention and control groups after stratification into blocks by state and practice size (the number of general practitioners in a practice) using a computer-generated randomisation list. Participant practitioners were not blinded to allocation.

\section{Participants}

Thirty-two practices (eight from each state) were recruited to the study through regional primary care organisations responsible for coordinating quality improvement activities at the local practice level. A total of 124 practices were approached to assess their eligibility. Eighty-one declined to participate; eight did not meet the inclusion criteria and three did not participate for other (various reasons). Eight practices in each of the four states provided consent.

Inclusion criteria were the use of computerised medical records that could be audited with the PCS Clinical Audit Tool (PENCAT) and employment of a practice nurse $(\mathrm{PN})$. PNs are registered nurses (generally bachelor degree qualified) who work in general practice and in collaboration with GPs, coordinate and provide preventive and chronic illness care. ${ }^{18}$

De-identified medical record data were extracted for patients who were aged 40-69 years and had attended the practice in the previous 12 months. Records of patients with heart disease, stroke, diabetes or chronic renal disease, cognitive impairment or severe mental illness (psychoses) were excluded based on their need for specialised assessment and management.

\section{Intervention}

The intervention was targeted at the practice level and aimed to improve the assessment and management of smoking; nutrition and weight; alcohol and physical activity (SNAP), ${ }^{19}$ cardiovascular and diabetes risk; blood pressure (BP) and lipids.

The intervention occurred over 6 months and comprised (1) small group training of practice staff; (2) feedback on audited performance; (3) a series of practice facilitation visits; and (4) provision of patient education resources and referral information (see box 1). The facilitation was based on quality improvement (QI) whereby each practice reviewed their performance and set and reviewed goals specific to their individual circumstances and resources. Facilitators also provided telephone support as needed to practices over 12 months. Facilitators were sourced from a local primary care organisation and all had expertise providing QI to practices. Facilitators also underwent specific training to provide the PEP intervention and were in turn supported by the research team.

\section{Outcomes}

The primary outcomes were the assessment and recording in the electronic medical record of smoking status, alcohol use, body mass index (BMI), waist circumference (WC), systolic and diastolic BP, fasting blood glucose, lipids (total cholesterol, high-density lipoprotein, low-density lipoprotein, triglycerides) and absolute cardiovascular (CV) risk (base on Framingham risk score adjusted for the Australian population ${ }^{20}$ ). Secondary outcomes were the self-reported assessment practices of GPs and PNs and their confidence when performing these assessments.

\section{Data collection}

Clinicians completed a questionnaire at baseline and 12 months. This questionnaire was based on work 


\section{Box 1 PEP Practice Intervention}

1. Written feedback and practice-based discussion of clinical record audit of recording and levels of behavioural and physiological risk factors (BMI, waist circumference, systolic $\mathrm{BP}$, alcohol consumption, smoking status, lipids, fasting glucose and absolute cardiovascular risk) for chronic vascular disease from the electronic medical record of each practice. These were compared with Australian evidence-based guidelines and standards.

2. Small group training (approximately $3 \mathrm{~h}$ duration) of all participating general practitioners and practice nurses based on the $5 \mathrm{As}$ for each of the risk factors using clinical scenarios and case studies to reflect on assessment, advice giving, goal setting, referral and follow-up of patients with abnormal risk factors. There was particular emphasis on the lifestyle management of these risk factors.

3. Trained practice facilitators visited and met with practice staff (for at least three 1-2 h) to develop and support the implementation of a plan to improve the prevention of vascular disease in the practice population. The plan for each practice was required to include improving the assessment and recording of risk factors. Practice goals to improve other aspects of vascular preventive care were flexibly determined for each practice based on need and the priority of participants. There were three structured visits over 3 months following the small group training.

4. Patient education resources for use by practice nurses and general practitioners and information on referral services and programmes within the local area were provided to each practice in written and electronic form for uploading into practice record systems. No specific prompts or templates for preventive care were used in the electronic record.

previously undertaken by the investigators with questions adapted from the Preventive Medicine Attitudes and Activities Questionnaire (PMAAQ). ${ }^{21}$ The instrument collected self-reported frequency of assessment of risk factors during clinical encounters, advice given and referral of patients identified to be at risk. We also asked clinicians about their confidence in assessing and managing risk factors. Principle component analysis was performed on the confidence questions which identified a single component with an Eigenvalue of 5.5 which explained $69 \%$ of the variance.

Deidentified clinical patient data were extracted using the PENCAT clinical audit software at baseline and 12 months. We extracted data related to recording and level of risk factors for $\mathrm{BMI}, \mathrm{WC}$, systolic BP, alcohol and smoking for patients aged 40-69 years and lipids, fasting blood glucose and absolute CV risk for patients aged 45-69 years (in accordance with the guidelines).

\section{Sample size}

The sample size calculation was based on the ability to detect an improvement of $10 \%$ between control and intervention groups in the recording of risk factors. For BMI with intra-cluster correlation coefficient (ICC) of 0.047 at $80 \%$ power at the $5 \%$ significance level, this gave a sample of 8700 patient records in each group. The same assumptions produce sample size estimates of 10800 and 11300 for LDL-cholesterol $(\mathrm{ICC}=0.059)$ and systolic BP $(\mathrm{ICC}=0.062)$, respectively.

\section{Analysis}

Practice and provider characteristics at baseline were compared between groups for those participating over the 12 months using univariate statistical tests $\left(\chi^{2}\right)$.

Primary analysis evaluated the change in recording of risk factors and levels of risk factors. Levels were defined as elevated for BMI $(>25)$, waist circumference (male $\geq 94 \mathrm{~cm}$, female $\geq 80 \mathrm{~cm})$, BP $(\geq 140 / 90)$, alcohol $(>2$ standard drinks/day), smoking (current), blood glucose $(>5.5 \mathrm{mmol} / \mathrm{L})$, total cholesterol $(\geq 4)$ and $\mathrm{CV}$ disease (CVD) risk ( $>10 \%$ over 5 years) based on evidence-based Australian guidelines. Secondary analysis evaluated the change in self-reported assessment and confidence in assessment by participating GPs and PNs.

Univariate statistical tests $\left(\chi^{2}\right.$ and $\mathrm{t}$ tests) were performed to examine difference between baseline and follow-up, and between intervention and control participants for the outcome variables at the level of $\mathrm{p}<0.05$.

Multilevel logistic regression models were used to examine those outcomes that were significant in the univariate analysis. This modelled dichotomous dependent variables for improvements in recording of CVD risk, BMI, WC, alcohol, BP and smoking at follow-up. These models examined the effect of the intervention on improved recording of risk factors adjusted for clustering of patients (level 1) within practices (level 2) and confounding effects of patient factors (age and gender) and practice characteristics (number of GPs and nurses and proportion of GPs/PNs working $\geq 10$ years in primary care).

Initially we fitted a baseline variance component or empty multilevel model (no independent variables) for each of the dependent variables, followed by the multilevel model with independent variables. The significance of the fixed and random parameter variance estimates (practice variance) was assessed using the Wald joint $\chi 2$ test statistic. The proportion of the practice level variance explained for each model was estimated as the difference in practice variance between baseline model (empty model) and each model with independent variables divided by the practice variance for the baseline model. All multilevel models were performed using MLwiN V.2.25. ${ }^{22}$

\section{Ethics and trial registration}

All participants gave full informed written consent. Clinical Trial Registration was obtained via the Australian and New Zealand Clinical Trials Register (ANZCTR): ACTRN12612000578808. We started the trial registration process with ANZCTR on the 15 May 2012. We entered the CTR registration form on the 21 May 2012 and received notification of the registration on 29 May 2012. 


\section{RESULTS}

\section{Practice and provider characteristics}

Of the 32 practices recruited, 16 were allocated to the PEP intervention and 16 to usual care (figure 1). Prior to baseline data collection, one intervention practice was excluded because of incompatibility between the electronic medical record and the data extraction programme and one control practice withdrew citing lack of capacity to continue participating in the study. A further three control practices were excluded later in the study when technical difficulties impeded the collection of audit data. The resulting sample comprised 15 intervention and 12 control practices. There was no difference between the two groups in relation to the number of
GPs in the practice (26\% were solo, $30 \%$ 2-4 GPs, $44 \%$ 5 or more GPs).

There were 83 GPs and 40 PNs enrolled in the study at baseline. At baseline 122 of the 123 practitioners who were enrolled in the study completed the questionnaire, and 97 practitioners completed both the baseline and follow-up questionnaires (70 GPs and 27 PNs).

There were no significant differences between intervention and control groups with respect to gender or in the number of practices that had staff aged 55 years or older, or those who had been working in general practice for 10 or more years. There were significant differences in the years in general practice and years working

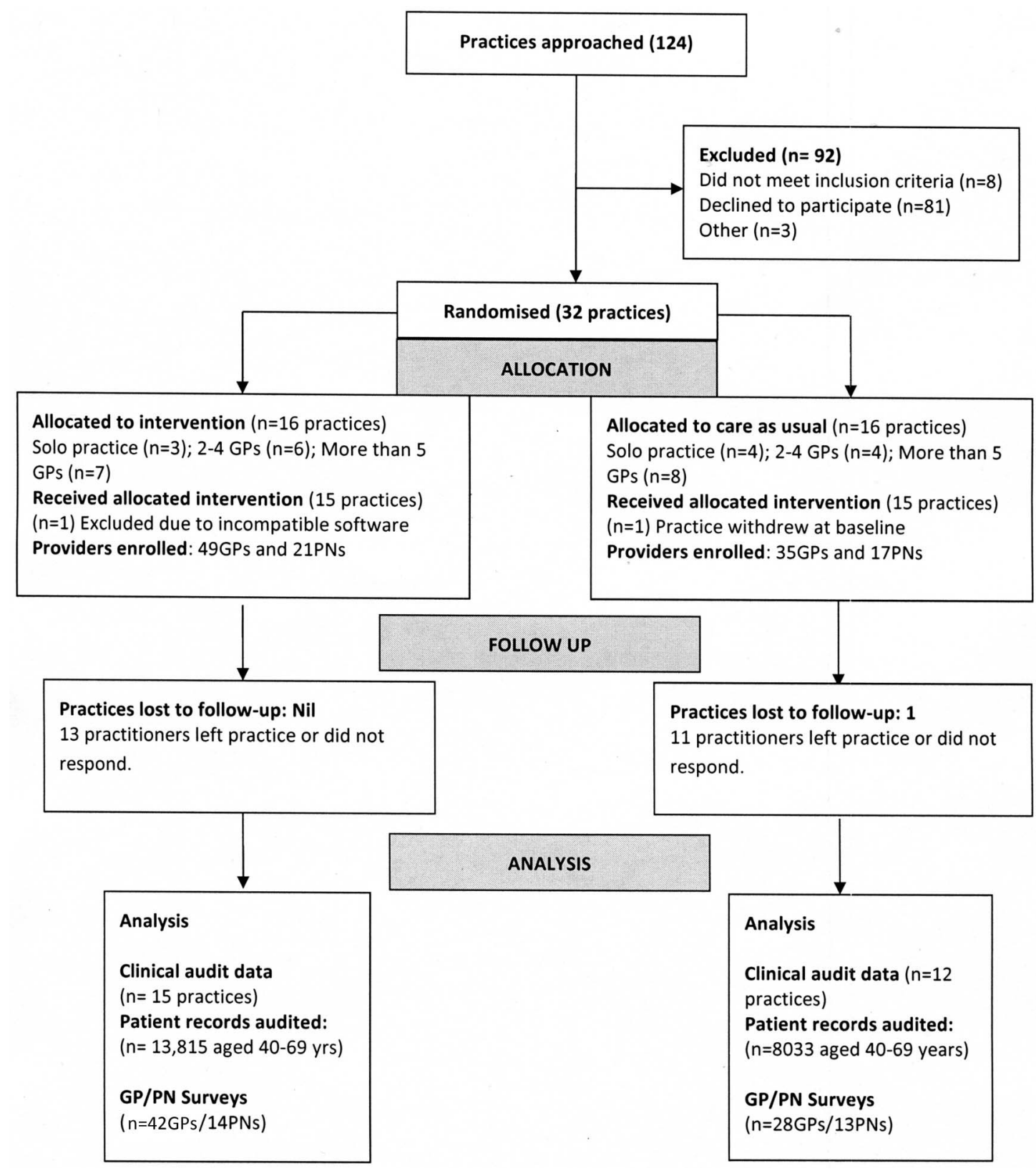

Figure 1. Consort flow chart. GP, general practitioners; PN, practice nurses. 
Table 1 Clinician characteristics (general practitioners and practice nurses)

\begin{tabular}{|c|c|c|c|c|}
\hline & $\begin{array}{l}\text { Intervention } \\
\mathrm{N}(\%)\end{array}$ & $\begin{array}{l}\text { Control } \\
\mathrm{N}(\%)\end{array}$ & $\begin{array}{l}\text { Total } \\
\mathrm{N}(\%) \\
\end{array}$ & $\begin{array}{l}\text { Comparison: } \\
\text { intervention vs control }\end{array}$ \\
\hline \multicolumn{5}{|l|}{ Gender } \\
\hline Female & $35(62)$ & $23(56)$ & $58(60)$ & \multirow{2}{*}{$\chi^{2}=0.18, p=0.5$} \\
\hline Male & $21(38)$ & $18(49)$ & $39(40)$ & \\
\hline \multicolumn{5}{|l|}{ Age (years) } \\
\hline $20-34$ & $7(13)$ & $2(5)$ & $9(9)$ & \multirow[t]{6}{*}{$\chi^{2}=1.16, p=0.3$} \\
\hline $35-44$ & $17(30)$ & $8(20)$ & $25(26)$ & \\
\hline $45-54$ & $20(36)$ & $16(39)$ & $36(37)$ & \\
\hline $55-64$ & $11(20)$ & $13(32)$ & $24(25)$ & \\
\hline $65+$ & 0 & $2(5)$ & $2(2)$ & \\
\hline Missing & $1(2)$ & 0 & $1(1)$ & \\
\hline \multicolumn{5}{|l|}{ Work } \\
\hline Full-time equivalent & $29(52)$ & $23(56)$ & $52(54)$ & \multirow{3}{*}{$\chi^{2}=0.06, p=0.9$} \\
\hline Part-time equivalent & $26(46)$ & $17(42)$ & $43(44)$ & \\
\hline Missing & $1(2)$ & $1(2)$ & $2(2)$ & \\
\hline \multicolumn{5}{|l|}{ Type } \\
\hline Family practitioner & $42(75)$ & $28(68)$ & $70(72)$ & \multirow[t]{2}{*}{$\chi^{2}=0.25, p=0.6$} \\
\hline Practice nurse & $14(25)$ & $13(32)$ & $27(28)$ & \\
\hline \multicolumn{5}{|l|}{ Years in GP } \\
\hline$<10$ & $27(48)$ & $13(32)$ & $40(42)$ & \multirow[t]{3}{*}{$\chi^{2}=2.4, p=0.03$} \\
\hline $10-19$ & $10(18)$ & $9(23)$ & $19(20)$ & \\
\hline $20+$ & $19(34)$ & $18(45)$ & $37(38)$ & \\
\hline \multicolumn{5}{|l|}{ Years in this practice } \\
\hline$<10$ & $41(74)$ & 17 (42) & $58(60)$ & \multirow[t]{3}{*}{$\chi^{2}=11.0, p=0.004$} \\
\hline $10-19$ & $8(15)$ & $12(29)$ & $20(21)$ & \\
\hline $20+$ & $6(11)$ & $12(29)$ & $18(19)$ & \\
\hline
\end{tabular}

Table 2 Proportion (\%) of primary care providers self-reporting frequency of and confidence in assessments

\begin{tabular}{|c|c|c|c|c|c|c|c|}
\hline \multirow[b]{2}{*}{ Assessment } & \multicolumn{3}{|c|}{$\begin{array}{l}\text { Intervention ( } \mathrm{n}=56 \text { baseline and } \\
\text { follow-up) }\end{array}$} & \multicolumn{3}{|c|}{$\begin{array}{l}\text { Control ( } n=41 \text { baseline and } \\
\text { follow-up) }\end{array}$} & \multirow{2}{*}{$\begin{array}{l}\text { Comparison } \\
\text { change } \\
\text { intervention/ } \\
\text { control }\end{array}$} \\
\hline & $\begin{array}{l}\text { Baseline } \\
\mathrm{N}(\%)\end{array}$ & $\begin{array}{l}\text { Follow-up } \\
\mathrm{N}(\%)\end{array}$ & $\begin{array}{l}\text { Per cent } \\
\text { change } \\
\text { BL to FU }\end{array}$ & $\begin{array}{l}\text { Baseline } \\
\mathrm{N}(\%)\end{array}$ & $\begin{array}{l}\text { Follow-up } \\
\mathrm{N}(\%)\end{array}$ & $\begin{array}{l}\text { Per cent } \\
\text { change } \\
\text { BL to FU }\end{array}$ & \\
\hline \multicolumn{8}{|c|}{ Frequency of often, usually or always assess the risk (for more than $60 \%$ of their patients) } \\
\hline Diet & $32(57.1)$ & $35(62.5)$ & 5.4 & $28(68.3)$ & $26(63.5)$ & -4.8 & $\chi^{2}=1.5, p=0.5$ \\
\hline Physical activity & $33(58.9)$ & 39 (69.6) & 10.7 & $29(70.7)$ & $29(70.7)$ & 0 & $\chi^{2}=1.4, p=0.5$ \\
\hline Smoking status & $42(75.0)$ & $41(73.2)$ & -1.8 & $35(85.4)$ & $37(90.2)$ & 4.8 & $\chi^{2}=0.7, p=0.7$ \\
\hline Alcohol use & $37(66.1)$ & $37(66.1)$ & 0 & $27(65.9)$ & 30 (73.2) & 7.3 & $\chi^{2}=1.0, p=0.6$ \\
\hline Blood pressure & 55 (98.2) & $51(91.1)$ & -7.1 & $35(85.4)$ & $28(92.7)$ & 7.3 & $\chi^{2}=4.3, p=0.05$ \\
\hline Fasting blood lipids & $42(75.0)$ & 44 (78.6) & 3.6 & $27(65.9)$ & $29(70.7)$ & 4.8 & $\chi^{2}=0.1, p=0.9$ \\
\hline Fasting blood glucose & $42(75.0)$ & $44(78.6)$ & 3.6 & 27 (65.9) & 29 (68.3) & 2.4 & $\chi^{2}=0.1, p=0.9$ \\
\hline Body mass index & $28(50.0)$ & $32(57.1)$ & 7.1 & $27(65.9)$ & $32(78.0)$ & 12.0 & $\chi^{2}=2.3, p=0.1$ \\
\hline Absolute cardiovascular risk* & $13(23.2)$ & 19 (33.9) & 10.7 & $20(48.8)$ & $13(31.7)$ & -17.1 & $\chi^{2}=6.7, p=0.03$ \\
\hline \multicolumn{8}{|c|}{$\begin{array}{l}\text { Proportion of providers stating that they were very confident (on a five-point scale of not at all, minimally, somewhat, } \\
\text { moderately and very confident) }\end{array}$} \\
\hline Smoking status & $23(41.1)$ & $32(57.1)$ & 17.5 & $19(46.3)$ & $18(43.9)$ & -2.4 & $\chi^{2}=3.1, p=0.08$ \\
\hline Nutrition & $12(21.4)$ & $17(30.4)$ & 9.0 & $13(31.7)$ & $10(24.4)$ & -7.3 & $\chi^{2}=0.9, p=0.3$ \\
\hline Risky drinking & $18(32.1)$ & 20 (35.7) & 3.6 & $14(34.1)$ & $10(24.4)$ & -9.7 & $\chi^{2}=2.5, p=0.1$ \\
\hline Physical activity & $17(30.4)$ & $23(41.1)$ & 10.7 & $12(29.3)$ & $12(29.3)$ & 0 & $\chi^{2}=1.0, p=0.3$ \\
\hline Readiness to change & 8 (14.3) & $16(28.6)$ & 14.3 & $9(22.0)$ & 5 (12.2) & -9.8 & $\chi^{2}=5.5, p=0.04$ \\
\hline Absolute cardiovascular risk ${ }^{*}$ & $16(28.6)$ & $25(44.6)$ & 16.0 & $16(39.0)$ & $13(31.7)$ & -7.3 & $\chi^{2}=5.3, p=0.03$ \\
\hline
\end{tabular}




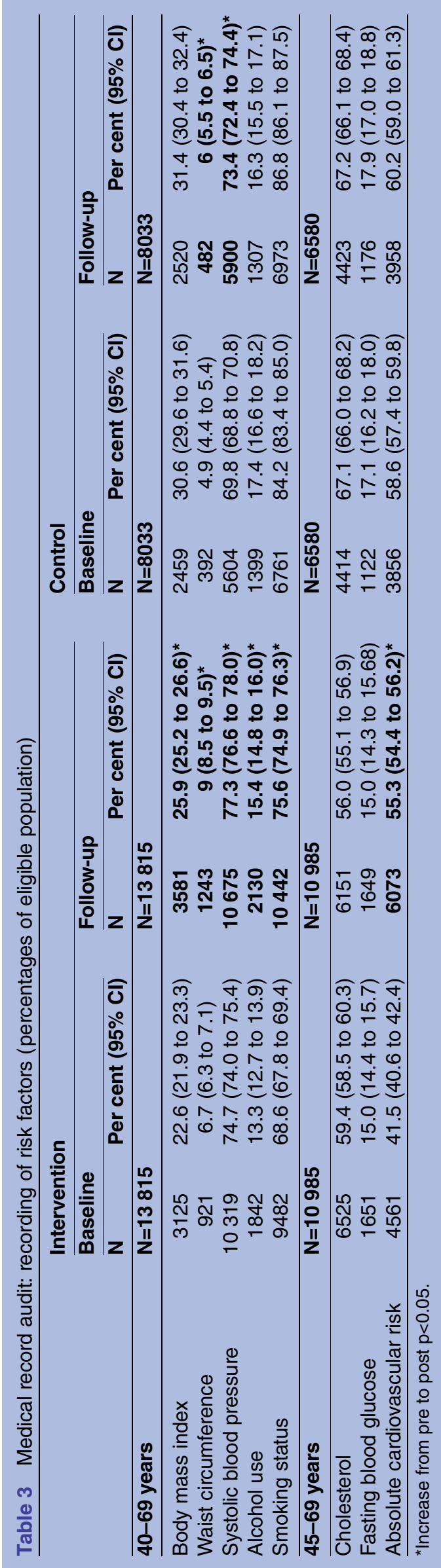

at the enrolled practice (which was longer for the control group; table 1).

\section{Provider self-reported quality of care}

Table 2 shows clinician self-reported frequency of, and confidence in risk factor assessment for those providers who responded at both baseline and 12 months. At baseline, clinicians reported frequently (often, usually or always) assessing risk factors (except cardiovascular risk), and there was little change at 12 months (except for CVD risk which improved in the intervention but not the control group; table 2). At baseline clinician confidence levels were low and at 12 months these had improved in relation to the assessment of absolute CVD risk and patient's readiness to change (table 2).

\section{Change in recording of risk factors at clinical record audit}

From the clinical record audit, 21848 patients aged 4069 years had both baseline and follow-up audit data (73\% of the total; 13815 intervention and 8033 control). Of these, 17565 were aged $45-69$ years (10 985 and 6580 respectively). Sixty-one per cent were female with similar proportions in the intervention and control groups $\left(\chi^{2}=2.7, p=0.1\right)$. At baseline the mean age overall was 52.9 years, 52.7 years in the intervention group compared to 53.2 years in the control group $(\mathrm{t}=4.28$, $\mathrm{p}<0.001)$.

The baseline audits of all practices identified scope for at a least a $10 \%$ improvement in the assessment and recording of all the risk factors except smoking which was also significantly higher for the control group compared to the intervention group at baseline $\left(\chi^{2}=641\right.$, $\mathrm{p}<0.0001)$. In univariate analysis the proportion of records from the intervention practices with recorded BMI, WC, systolic BP, smoking, alcohol and CVD risk improved over the 12-month intervention period. In the control practices the percentage of records with waist circumference and systolic BP also improved (table 3). A greater proportion of gaps in recording for BMI, waist circumference, alcohol, smoking, cholesterol and absolute CVD risk were filled at follow-up in the intervention compared to the control group (table 4).

Multilevel, multivariate analyses were performed comparing the likelihood of a change in risk factor recording (ie, where risk factors were not recorded at baseline but were subsequently recorded at follow-up). After adjusting for age group and gender of patients, number of GPs and PNs in the practice and the proportion working in the practice for 10 or more years, the likelihood of change was significantly greater in the intervention compared to control group for WC (OR, 2.52 (95\% CI 1.30 to 4.91)) alcohol consumption (OR, 2.19 (CI 1.04 to 4.64$)$ ), smoking status (OR, 2.24 (1.17 to 4.29)) and cardiovascular absolute risk (OR, 1.50 (1.04 to 2.18); table 5).

Patient age increased the likelihood of an improvement in recorded CVD risk and cholesterol. Younger patients had a higher probability of waist circumference 
Table 4 Proportion (\%) of records with missing baseline data but newly recorded risk factors at follow-up.

\begin{tabular}{|c|c|c|c|}
\hline & Intervention \% (95\% Cl) & Control \% (95\% Cl) & $\begin{array}{l}\text { Comparison of change } \\
\text { between intervention/control }\end{array}$ \\
\hline 40-69 years & $\mathrm{N}=13815$ & $\mathrm{~N}=8033$ & \\
\hline Body mass index & 9.1 (6.9 to 11.3$)$ & 7.6 (5.3 to 9.8$)$ & $\chi^{2}=14,8, p<0.0001$ \\
\hline Waist circumference & 4.9 (2.8 to 7.1$)$ & 2.1 (0 to 4.2$)$ & $\chi^{2}=110, p<0.0001$ \\
\hline Systolic blood pressure & 9.8 (7.6 to 12.0$)$ & 9.1 (6.8 to 11.4$)$ & $\chi^{2}=2.7, p=0.1$ \\
\hline Alcohol use & 6.3 (4.1 to 8.5$)$ & 3.3 (1.1 to 5.4$)$ & $\chi^{2}=95, p<0.0001$ \\
\hline Smoking status & 6.9 (4.8 to 9.1$)$ & $2.6(0.5$ to 4.8$)$ & $\chi^{2}=185, p<0.0001$ \\
\hline 45-69 years & $\mathrm{N}=10985$ & $\mathrm{~N}=6580$ & \\
\hline Cholesterol & 16.4 (15.8 to 17.2$)$ & 13.5 (12.6 to 14.3$)$ & $\chi^{2}=19.4, p<0.0001$ \\
\hline Fasting blood glucose & 4.5 (4.1 to 4.9$)$ & $4.6(4.1$ to 5.1$)$ & $\chi^{2}=0.7, p=0.4$ \\
\hline Absolute cardiovascular risk & $14.9(14.2$ to 15.5$)$ & 8.9 (8.2 to 9.6$)$ & $\chi^{2}=114, p<0.0001$ \\
\hline
\end{tabular}

and BP being recorded. Smaller practices and practices with two or more nurses were more likely to improve assessment and recording of BP over the 12 months. However, significant interpractice variation remained unexplained by the variables included in the regression analysis (table 6).

\section{Change in patient outcomes-clinical audit}

While there was a significant burden of 'risk' across the whole audited population, where data was recorded no significant changes in the proportion of patients at increased risk between baseline and follow-up were found in either the intervention or control group (table 6).

\section{DISCUSSION}

In this multicenter cluster randomised controlled trial the PEP intervention was associated with an improved recording of CVD risk, WC, alcohol use and smoking status in comparison with the control group (by between $2 \%$ and $6 \%$ for individual risk factors). Small improvements in recording preventive care are consistent with previous evaluations of practice facilitation on preventive care $^{23-25}$ underlining the challenge in achieving systemic quality improvement. While not specifically assessed in this trial, the failure to achieve better results with facilitation may also reflect the variable capacity of practices to alter their systems and routines ${ }^{26}$ or the perceived importance of preventive care. Achieving greater improvements may also require greater intervention effort or a different approach more closely tailored to the context of individual practice needs. ${ }^{26}$

Those older patients, who are at greater risk, were appropriately more likely to have their CVD risk recorded. However, they were less likely to have documented BP and WC, both of which can be readily assessed during clinical encounters. Regular assessment of $\mathrm{BP}$ is no less important in older adults ${ }^{28}$ and waist circumference is associated with significantly higher mortality in the elderly after adjusting for BMI. ${ }^{29}$

We found a disparity between a high reported frequency of assessments by GPs and PNs with much lower frequency of recording in the medical record. This is consistent with earlier research demonstrating inconsistency between the frequency of self-reported assessment and more objective measures. ${ }^{30}$ Over half of the GPs and PNs reported not being confident in various preventive assessments at baseline, and remained so after a year, despite some improvement in the intervention group. This suggests the importance of developing provider skill and confidence as pre-requisites for further improvement.

The level of 'risk' in the patient population was high and comparable with that reported generally for Australians in this age group. Despite this, where recorded, no change was found during the trial in the proportion of patients who were at risk. This is an important negative finding and is potentially explained by a couple of intervention characteristics. The PEP intervention targeted the preventive care provided by practices and practitioners for their patients, rather than providing new services directly to patients. The intervention period was also relatively short being of 6 months duration only. We know that effective lifestyle interventions can require significant time. ${ }^{23} 31$ There are system barriers that may reduce the capacity of practices to improve the frequency of referral. Barriers to referral include patient (health literacy), ${ }^{32}$ practice (team roles and time) ${ }^{33}$ and system level (cost and funding, information and communication systems) factors. ${ }^{34} 35$ The implication of this may be that more direct services to patients need to be provided in addition to practice improvement strategies to achieve change in health outcomes.

There are a number of limitations of our trial. Practices were urban and thus we cannot generalise these findings to rural or remote general practice. The trial design did not allow blinding of practitioners to their allocation. Practices were smaller than those participating in a national audit of general practices $)^{36}$ with respect to size of practice $(43 \%$ had four or more GPs compared with $62.8 \%$ in the national data). All practices in our study were urban or semiurban compared with $73.9 \%$ of those national data. 
Table 5 Multilevel logistic regression models for being absent at baseline but recorded at follow-up in intervention compared to control group

\begin{tabular}{|c|c|c|c|c|c|c|c|}
\hline & $\begin{array}{l}\text { CVD risk } \\
\text { OR }(95 \% \mathrm{Cl})\end{array}$ & $\begin{array}{l}\text { BMI } \\
\text { OR (95\% CI) }\end{array}$ & $\begin{array}{l}\text { Waist } \\
\text { circumference } \\
\text { OR }(95 \% \mathrm{Cl})\end{array}$ & $\begin{array}{l}\text { Alcohol } \\
\text { OR }(95 \% \mathrm{Cl})\end{array}$ & $\begin{array}{l}\text { Blood pressure } \\
\text { OR }(95 \% \mathrm{Cl})\end{array}$ & $\begin{array}{l}\text { Smoking } \\
\text { OR }(95 \% \mathrm{CI})\end{array}$ & $\begin{array}{l}\text { Cholesterol } \\
\text { OR }(95 \% \mathrm{CI})\end{array}$ \\
\hline \multicolumn{8}{|l|}{ Allocation } \\
\hline $\begin{array}{l}\text { Control } \\
\text { (reference) } \\
(n=8033)\end{array}$ & 1.0 & 1.0 & 1.0 & 1.0 & 1.0 & 1.0 & 1.0 \\
\hline $\begin{array}{l}\text { Intervention } \\
(n=13 \text { 815) }\end{array}$ & 1.50 (1.04 to 2.18$)$ & $1.28(0.87$ to 1.88$)$ & $2.52(1.30$ to 4.91$)$ & 2.19 (1.04 to 4.64$)$ & $1.12(0.79$ to 1.58$)$ & 2.24 (1.17 to 4.29$)$ & $1.29(0.88$ to 1.91$)$ \\
\hline \multicolumn{8}{|l|}{ Patient age } \\
\hline $\begin{array}{l}<50 \text {-year } \\
\text { (reference) }\end{array}$ & 1.0 & 1.0 & 1.0 & 1.0 & 1.0 & 1.0 & 1.0 \\
\hline 50-59-year & 1.15 (1.04 to 1.27$)$ & 0.95 (0.53 to 1.70$)$ & 0.68 (0.59 to 0.79$)$ & $1.10(0.97$ to 1.25$)$ & $0.85(0.77$ to 0.94$)$ & 0.97 (0.85 to 1.11$)$ & $1.22(1.11$ to 1.34$)$ \\
\hline$>59$ years & $1.13(1.01$ to 1.26$)$ & 0.96 (0.85 to 1.08$)$ & 0.78 (0.66 to 0.92$)$ & $1.12(0.97$ to 1.29$)$ & 0.55 (0.49 to 0.63$)$ & $0.93(0.80$ to 1.08$)$ & $1.08(0.97$ to 1.20$)$ \\
\hline \multicolumn{8}{|l|}{ Patient gender } \\
\hline $\begin{array}{l}\text { Male } \\
\text { (reference) }\end{array}$ & 1.0 & 1.0 & 1.0 & 1.0 & 1.0 & 1.0 & 1.0 \\
\hline Female & 0.99 (0.99 to 1.09$)$ & 0.96 (0.87 to 1.06$)$ & 0.94 (0.82 to 1.07$)$ & 0.98 (0.88 to 1.10$)$ & $1.04(0.95$ to 1.15$)$ & $0.93(0.83$ to 1.05$)$ & $1.06(0.98$ to 1.15$)$ \\
\hline \multicolumn{8}{|c|}{ Number of general practitioners (GP) in practice } \\
\hline $\begin{array}{l}1-3 \mathrm{GPs} \\
\text { (reference) }\end{array}$ & 1.0 & 1.0 & 1.0 & 1.0 & 1.0 & 1.0 & 1.0 \\
\hline$>3 \mathrm{GPs}$ & 0.89 (0.58 to 1.37$)$ & $1.16(0.78$ to 1.72$)$ & $1.64(0.75$ to 3.59$)$ & $1.95(0.81$ to 4.68$)$ & $0.64(0.43$ to 0.96$)$ & $1.06(0.54$ to 2.06$)$ & $0.86(0.54$ to 1.35$)$ \\
\hline \multicolumn{8}{|c|}{ Number of practice nurses (PN) in practice } \\
\hline $\begin{array}{l}\text { 1or less PN } \\
\text { (reference) }\end{array}$ & 1.0 & 1.0 & 1.0 & 1.0 & 1.0 & 1.0 & 1.0 \\
\hline$>1 \mathrm{PN}$ & 1.51 (0.99 to 2.31$)$ & $1.28(0.87$ to 1.88$)$ & $1.32(0.62$ to 2.82$)$ & $0.83(0.36$ to 1.96$)$ & $1.61(1.08$ to 2.40$)$ & $0.92(0.48$ to 1.76$)$ & $1.35(0.87$ to 2.11$)$ \\
\hline \multicolumn{8}{|c|}{ Percentage of GPs/PNs working in primary care $\geq 10$ years } \\
\hline 0 (reference) & 1.0 & 1.0 & 1.0 & 1.0 & 1.0 & 1.0 & 1.0 \\
\hline$>0$ or more & $0.72(0.37$ to 1.40$)$ & $1.02(0.55$ to 1.88$)$ & $1.01(0.30$ to 3.36$)$ & $0.90(0.24$ to 3.41$)$ & 0.55 (0.30 to 1.03$)$ & $0.41(0.15$ to 1.14$)$ & 1.34 (0.67 to 2.71$)$ \\
\hline $\begin{array}{l}\text { Between } \\
\text { practice } \\
\text { variance (SE) }\end{array}$ & $0.201(0.062)$ & $0.159(0.051)$ & $0.640(0.197)$ & $0.869(0.251)$ & $0.174(0.054)$ & $0.482(0.145)$ & $0.231(0.069)$ \\
\hline $\begin{array}{l}\text { Percentage of } \\
\text { Variance } \\
\text { explained }\end{array}$ & 14.8 & 32.3 & 46.9 & 33.1 & 11.7 & 0 & 37.2 \\
\hline
\end{tabular}




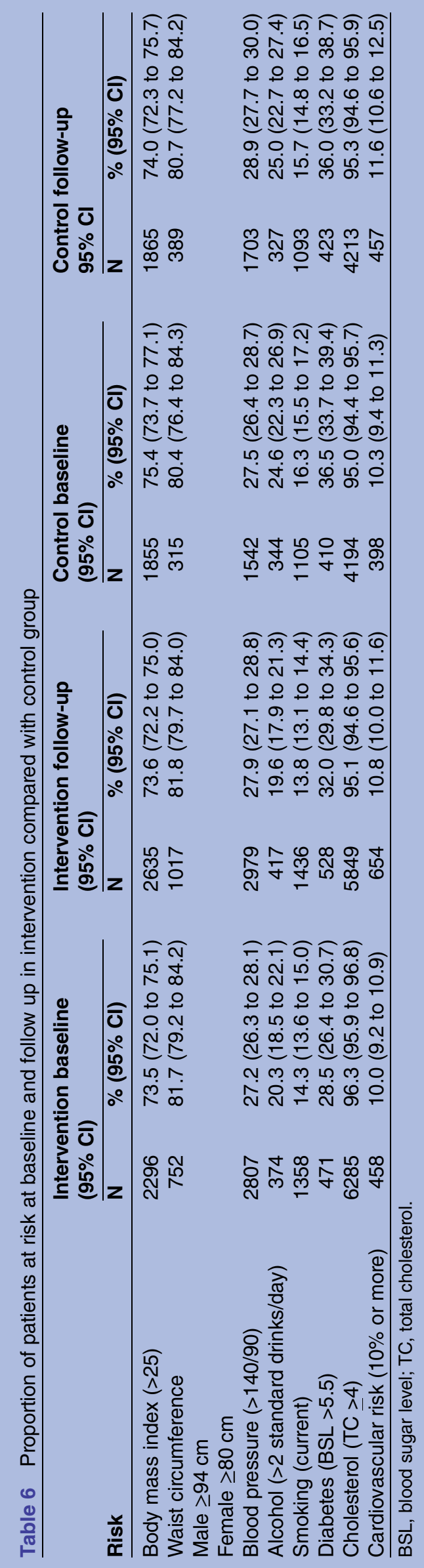

Although largely comparable, there were some differences at baseline in practitioner years in general practice and in their current practice between intervention and control groups. Furthermore there were differences at baseline in the recorded frequency of smoking which made it more difficult to show improvement in this risk factor the control group. In addition, the provider questionnaire relied on self-report and as such was subject to recall and social desirability bias. While all practitioners agreed to the assessment goals, the implementation of the intervention with patients was constrained by their lack of confidence and other practical constraints. The number of practitioners was too small for multilevel analysis of their self-reported data.

The sample size was lower in the control practices due to the smaller number of practices and practitioners and thus it was insufficiently powered to show a $10 \%$ or less difference in BP and cholesterol recording between intervention and control practices. Patient medical record audits did not allow examination of other patient characteristics such as health literacy and did not allow for the measurement of assessments that had been recorded in other ways by the GP. Only a minority of the interpractice variance in CVD risk, BMI and BP recording was explained by variables included in the regression model suggesting that other factors need to be explored.

\section{CONCLUSION}

The PEP intervention involved clinical audit, provider training, practice facilitation visits and linkage to other services. It had a positive impact on provider behaviour, as evidenced by the improved assessment and recording of smoking, WC, alcohol and absolute CVD risk. Effective implementation of preventive care in PHC is however a complex iterative process that requires ongoing support and monitoring at the patient, provider, practice and system levels. This result is extremely relevant to the role of primary care organisations in Australia which are charged with improving the quality of care. Our trial did however show no impact on patient risk. Achieving the latter may require more intensive facilitation over a longer time frame, changes to the electronic medical record to prompt preventive care, additional support of practices to make changes to their work flow and providing interventions that directly involve patients (such as telephone or online coaching).

\section{Author affiliations}

${ }^{1}$ Centre for Primary Health Care and Equity, University of New South Wales Australia, Sydney, New South Wales, Australia

${ }^{2}$ Discipline of General Practice, School of Medicine, Flinders University, Adelaide, South Australia, Australia

${ }^{3}$ Academic Discipline of General Practice, University of Queensland, Brisbane, Queensland, Australia

${ }^{4}$ Southern Academic Primary Care Research Unit, School of Primary Health Care, Monash University, Notting Hill, Victoria, Australia

${ }^{5}$ Department of General Practice, Monash University, Notting Hill, Victoria, Australia 
${ }^{6}$ Faculty of Health Sciences and Medicine, Bond University, Gold Coast, Queensland, Australia

${ }^{7}$ School of Public Health and Community Medicine, University of New South Wales, Sydney, New South Wales, Australia

Contributors MFH led the development of the design of the study and its protocol and the implementation of the trial. MFH, JL, GR, DM, MvD, CDM JS, JL, NZ, UWJ, SMP and GP-D contributed to the design of the trial, development of the data collection instruments and trial processes and coordination of the trial across sites. SMP coordinated the acquisition of trial data and MFH, SMP and UWJ collated and analysed the data. All authors contributed to the interpretation of the data and provided intellectual input to the manuscript and critical review of the content. All authors approved the final version for publication and agree to be accountable for the integrity of the content, and responsible for any issues that arise from publication of the trial data.

Collaborators The following are members of the PEP (Preventive Evidence into Practice) Partnership Group: Professor Mark Harris (Chief Investigator and Study Lead) University of NSW Australia. Professor Nicholas Zwar (Chief Investigator) University of NSW Australia. Associate Professor John Litt (Chief Investigator) Flinders University Australia. Professor Danielle Mazza (Chief investigator) Monash University Australia. Professor Mieke van Driel (Chief Investigator) University of Queensland, Australia. Professor Richard Taylor (Chief Investigator) University of NSW Australia. Professor Grant Russell (Chief Investigator) Monash University Australia. Professor Chris Del Mar (Associate Investigator) Bond University Australia. Dr Jane Lloyd (Associate Investigator) University of NSW Australia. Associate Professor Jane Smith (Associate Investigator) Bond University Australia. Associate Professor Elizabeth Denney-Wilson (Associate Investigator) University of Technology Australia. Dr Rachel Laws (Associate Investigator) Deakin University Australia. Dr Teri Snowdon, Ms Helen Bolger-Harris and Mr Stephan Groombridge (Supporting Partner) Royal Australian College of General practitioners (RACGP). Dr Stan Goldstein and Ms Teresa Howarth (Supporting Partner) Bupa Health Foundation Australia. Dr Nancy Huang and Ms Jinty Wilson (Supporting Partner) National Heart Foundation of Australia.

Funding Funding for this trial was received from the National Health and Medical Research Council (NHMRC) of Australia under a Partnership Grant (grant number 568979) (2010). Funding was also provided from the Royal Australian College of General Practitioners (RACGP), the Heart Foundation and Bupa Health Foundation. MFH was funded by a National Health and Medical Research Council senior principal research fellowship.

Competing interests None declared.

Patient consent Obtained.

Ethics approval National Research and Evaluation Ethics Committee of the Royal Australian College of General Practitioners (NREEC 10-002).

Provenance and peer review Not commissioned; externally peer reviewed.

Data sharing statement No additional data are available.

Open Access This is an Open Access article distributed in accordance with the Creative Commons Attribution Non Commercial (CC BY-NC 4.0) license, which permits others to distribute, remix, adapt, build upon this work noncommercially, and license their derivative works on different terms, provided the original work is properly cited and the use is non-commercial. See: http:// creativecommons.org/licenses/by-nc/4.0/

\section{REFERENCES}

1. Lim SS, Vos T, Flaxman AD, et al. A comparative risk assessment of burden of disease and injury attributable to 67 risk factors and risk factor clusters in 21 regions, 1990-2010: a systematic analysis for the Global Burden of Disease Study 2010. Lancet 2012;380:2224-60.

2. Australian Institute of Health and Welfare. Risk factors contributing to chronic disease. Canberra: AlHW, 2012.

3. Royal Australian College of General Practitioners (RACGP). Guidelines for preventive activities in general practice. 8th edn. East Melbourne: RACGP, 2012.
4. Lu S, MF H. Prevention of diabetes and heart disease-patient perceptions on risk, risk assessment and the role of their GP in preventive care. Aust Fam Physician 2013;42:328-31.

5. Hung DY, Rundall TG, Tallia AF, et al. Rethinking prevention in primary care: applying the chronic care model to address health risk behaviors. Milbank Q 2007;85:69-91.

6. National Vascular Disease Prevention Alliance (NVDPA). Guidelines for the management of absolute cardiovascular disease risk. Canberra: Stroke Foundation, 2012.

7. National Health and Medical Research Council (NHMRC). Clinical practice guidelines for the management of overweight and obesity in adults, adolescents and children in Australia. Melbourne National Health and Medical Research Council, 2013.

8. Goldstein MG, Whitlock EP, DePue J. Multiple behavioral risk factor interventions in primary care. Summary of research evidence. $A m \mathrm{~J}$ Prev Med 2004;27(2 Suppl):61-79.

9. Vallis $\mathrm{M}$, Piccinini-Vallis $\mathrm{H}$, Sharma $\mathrm{AM}$, et al. Clinical review: modified 5 As: minimal intervention for obesity counseling in primary care.. Can Fam Physician 2013;59:27-31.

10. Dosh SA, Holtrop JS, Torres T, et al. Changing organizational constructs into functional tools: an assessment of the $5 \mathrm{~A}$ 's in primary care practices. Ann Fam Med 2005;3(Suppl 2):S50-2.

11. Jay M, Gillespie C, Schlair S, et al. Physician's use of the 5 As in counseling obese patients: is the quality of counseling associated with patients' motivation and intention to lose weight? BMC Health Serv Res 2010;10:159.

12. Ampt A, Amoroso $C$, Harris MF, et al. Attitudes, norms and controls influencing lifestyle risk factor management in general practice. $B M C$ Fam Pract 2009;10:59.

13. Wolff $\mathrm{S}$, Massett $\mathrm{H}$, Weber D, et al. Opportunities and barriers to disease prevention counseling in the primary care setting: a multisite qualitative study with US health consumers. Health Promot Int 2010;25:265-76.

14. Amoroso C, Harris MF, Ampt A, et al. The 45-year-old health check -feasibility and impact on practices and patient behaviour. Aust Fam Physician 2009;38:358-62.

15. Harris MF, Lloyd J, Litt $\mathrm{J}$, et al. Preventive evidence into practice (PEP) study: implementation of guidelines to prevent primary vascular disease in general practice protocol for a cluster randomised controlled trial. Implement Sci 2013;8:8.

16. Harris MF, LLoyd J. The role of Australian primary health care in the prevention of chronic disease. Australian National Preventive Health Agency, 2012.

17. Mazza D, Harris MF. Improving implementation of evidence-based prevention in primary care. Med J Aust 2010;193:101-2.

18. Keleher H, Joyce C, Parker R, et al. Practice nurses in Australia: current issues and future directions. Med J Aust 2007;187:108-10.

19. Royal Australian College of General Practitioners (RACGP). Smoking, Nutrition, Alcohol and Physical activity (SNAP). A population health guide to behavioural risk factors in general practice. Edited by Care TRACoGPNSCQ. Melbourne: RACGP, 2004.

20. Alliance. NVDP. Guidelines for the assessment of absolute cardiovascular disease risk. Melbourne: National Heart Foundation of Australia, 2009.

21. Murphy KA, Yeazel M, Center BA. Validity of residents' self-reported cardiovascular disease prevention activities: the Preventive Medicine Attitudes and Activities Questionnaire. Prev Med 2000;31:241-8.

22. Rashbash J, Browne W, Healey M, et al. A user's guide to MLwiN version 2.25. Centre for Multilevel Modelling, University of Bristol, 2012.

23. Litt JC. Exploration of the delivery of prevention in the general practice setting. Adelaide Flinders University, 2007.

24. Lemelin J, Hogg W, Baskerville N. Evidence to action: a tailored multifaceted approach to changing family physician practice patterns and improving preventive care. CMAJ 2001;164:757-63.

25. Hogg W, Lemelin J, Moroz I, et al. Improving prevention in primary care: evaluating the sustainability of outreach facilitation. Can Fam Physician 2008;54:712-20.

26. Klabunde CN, Lanier D, Breslau ES, et al. Improving colorectal cancer screening in primary care practice: innovative strategies and future directions. J Gen Intern Med 2007;22:1195-205.

27. Nutting PA, Crabtree BF, Miller WL, et al. Transforming physician practices to patient-centered medical homes: lessons from the national demonstration project. Health Aff (Millwood) 2011;30: 439-45.

28. Mancia G, Fargard R, Narkiewicz K, et al. 2013 ESH/ESC Guidelines for the management of arterial hypertension. Eur Heart $J$ 2013;34:2159-219.

29. Janssen I, Katzmarzyk PT, Ross R. Body mass index is inversely related to mortality in older people after adjustment for waist circumference. J Am Geriatr Soc 2005;53:2112-18. 
30. Davis DA, Mazmanian PE, Fordis M, et al. Accuracy of physician self-assessment compared with observed measures of competence: a systematic review. JAMA 2006;296:1094-102.

31. Yarnall KS, Pollak KI, Østbye T, et al. Primary care: is there enough time for prevention? Am J Public Health 2003;93:635-41.

32. Taggart J, Williams A, Dennis S, et al. A systematic review of interventions in primary care to improve health literacy for chronic disease behavioral risk factors. BMC Fam Pract 2012;13:49.

33. Ghorob A, Bodenheimer T. Sharing the care to improve access to primary care. N Engl J Med 2012;366:1955-7.

34. Baker R, Camosso-Stefinovic J, Gillies C, et al. Tailored interventions to overcome identified barriers to change: effects on professional practice and health care outcomes. Cochrane Database Syst Rev 2010;(3):CD005470.

35. Baskerville NB, Liddy C, Hogg E. Systematic review and meta-analysis of practice facilitation within primary care settings. Ann Fam Med 2012;10:63-74.

36. Britt $\mathrm{H}$, Family medicine research $C$, university of $S$, beach: general practice activity in Australia 2011-12: BEACH, bettering the evaluation and care of health. Sydney: Sydney University Press, 2012.

37. National Vascular Disease Prevention Alliance. Guidelines for the management of absolute cardiovascular disease risk. Canberra: Stroke Foundation, 2012. 